\title{
Geographical speciation related to Pleistocene range shifts in the western Mediterranean mountains (Reseda sect. Glaucoreseda, Resedaceae)
}

\author{
Santiago Martín-Bravo, ${ }^{1}$ Virginia Valcárcel, ${ }^{1}$ Pablo $\operatorname{Vargas}^{2}$ \& Modesto Luceño ${ }^{1}$ \\ 1 Department of Molecular Biology and Biochemical Engineering, Pablo de Olavide University, ctra. de Utrera km 1, 41013, \\ Sevilla, Spain \\ 2 Botanic Garden of Madrid, CSIC, Pza. Murillo $n^{\circ}$ 2, 28014, Madrid, Spain \\ Author for correspondence: Santiago Martín-Bravo, smarbra@upo.es
}

\begin{abstract}
Reseda sect. Glaucoreseda is a monophyletic group composed of five endemic tetraploid species with a disjunct distribution in the high mountains and plateaus of the Iberian Peninsula and Morocco. It was previously suggested that range shifts induced by Quaternary glaciations played an important role in the speciation of the group. We studied the evolution of $R$. sect. Glaucoreseda in order to infer historical range dynamics and speciation processes, and to understand current distributional patterns. Phylogeographic analyses were performed using nuclear ribosomal ITS and plastid trnL-F and $r p s 16$ sequences. Cloning of additive ITS sequences was carried out to elucidate the origin of intra-individual polymorphisms. A dated phylogeny based on ITS and cpDNA ( $r b c L$, matK, trnL-F) sequences was used to estimate divergence times of $R$. sect. Glaucoreseda. Time estimates using Penalized Likelihood analyses indicate a late Pleistocene diversification of $R$. sect. Glaucoreseda. Incomplete lineage sorting of ancestral polymorphisms due to recent divergence, rather than rampant hybridisation, is suggested as the main cause of the phylogenetic incongruence detected between nuclear and plastid datasets. Our results support the vicariance hypothesis for population disjunctions in the Iberian Peninsula, in which an ancestral, widespread species could have undergone differentiation by Quaternary interglacial fragmentation. In contrast, long-distance dispersal across the Strait of Gibraltar may have been involved in the colonisation of North African plateaus by R. battandieri.
\end{abstract}

Keywords lineage sorting; mountain endemics; phylogeography; Pleistocene glaciations; Reseda section Glaucoreseda; vicariance; western Mediterranean

\section{IINTRODUCTION}

The wealth of molecular phylogeographic studies on European mountain taxa during the last decade have clearly demonstrated the important effect of Quaternary glaciations on their current geographical distribution and genetic diversity (see Comes \& Kadereit, 1998, 2003). These recurrent climatic changes caused cyclic expansions and contractions in the distribution ranges of plant species. Disjunct populations originated during contraction periods were potentially submitted to divergence processes driven by reproductive isolation due to geographical barriers, and genetic drift, which are key mechanisms for plant evolution and speciation. However, geographical isolation of mountain plants during interglacial cycles may have been too short to foster divergence, and glacial recolonisation frequently enabled secondary contacts between disjunct populations, preventing from complete speciation (Comes \& Kadereit, 1998; Kadereit \& al., 2004). This is particularly so because glacial periods were considerably longer (ca. 70,00090,000 years) than interglacial ones (ca. 10,000-26,000 years). As a result, range dynamics during Quaternary climatic oscillations markedly shaped the current genetic structure of many species (i.e., Kropf \& al., 2003; Noyes, 2006; Dixon \& al., 2007), but the question of whether they promoted speciation is still under debate (Zhang \& al., 2001; Kadereit \& al., 2004;
Parisod \& Besnard, 2007). The assessment of divergence times through the use of molecular dating is providing a growing evidence of plant speciation events during the Quaternary (Zhang \& al., 2001, 2004; Comes \& Kadereit, 2003; Kadereit $\&$ al., 2004). In addition, intraspecific differentiation patterns during the Quaternary have also been documented for several mountain taxa (reviewed in Vargas, 2003; Kadereit \& Comes, 2005; Schönswetter \& al., 2005).

The genetic structure of plant populations is strongly influenced by both common ancestry and interpopulation genetic exchange (i.e., Schaal \& al., 1998). Vicariance has been postulated as the predominant process shaping the geographical and genetic structure of European mountain plants (Kropf \& al., 2006, 2008), although long-distance dispersal has also been proposed to account for plant disjunctions (Zhang \& al., 2001; Kropf \& al., 2006; Puscas \& al., 2008). Recurrent periods of glacial recolonisation of inter-mountain lowland areas by mountain plants and interglacial range fragmentation may have facilitated admixture processes between divergent lineages (i.e., reticulation) and differential sorting of ancestral polymorphism in isolated populations. The footprint of these mechanisms is frequently reflected in incongruent evolutionary histories inferred from different genomes (i.e., nuclear vs. plastid). Unravelling whether hybridisation or incomplete lineage sorting are involved in the discordance between plastid and nuclear phylogenetic signals 
may be a difficult task, above all because they may be acting in concert (Wendel \& Doyle, 1998; Albaladejo \& al., 2005).

Reseda sect. Glaucoreseda (Glaucoreseda hereafter) is composed of five species endemic to the high mountain ranges and plateaus of the Iberian Peninsula and Morocco (Fig. 1): $R$. battandieri, from the Central Moroccan plateaus, $R$. complicata, restricted to the summits of Sierra Nevada, $R$. glauca, with a disjunct distribution in the Cantabrian Mountains and the Pyrenees, R. gredensis, from the Spanish Sierra de Gredos and extremely rare in the Portuguese Serra da Estrela (Central Massif), and $R$. virgata, occurring in the central-northern Iberian plateau. Therefore, Glaucoreseda species are present in all the main mountain ranges of the Iberian Peninsula, which constitute its main centres of plant biodiversity, harbouring approximately $60 \%$ of its endemic species (Gómez-Campo \& Malato-Beliz, 1985). The high physiographic complexity of the Iberian Peninsula probably allowed long-term survival and differentiation of species during Quaternary climatic oscillations

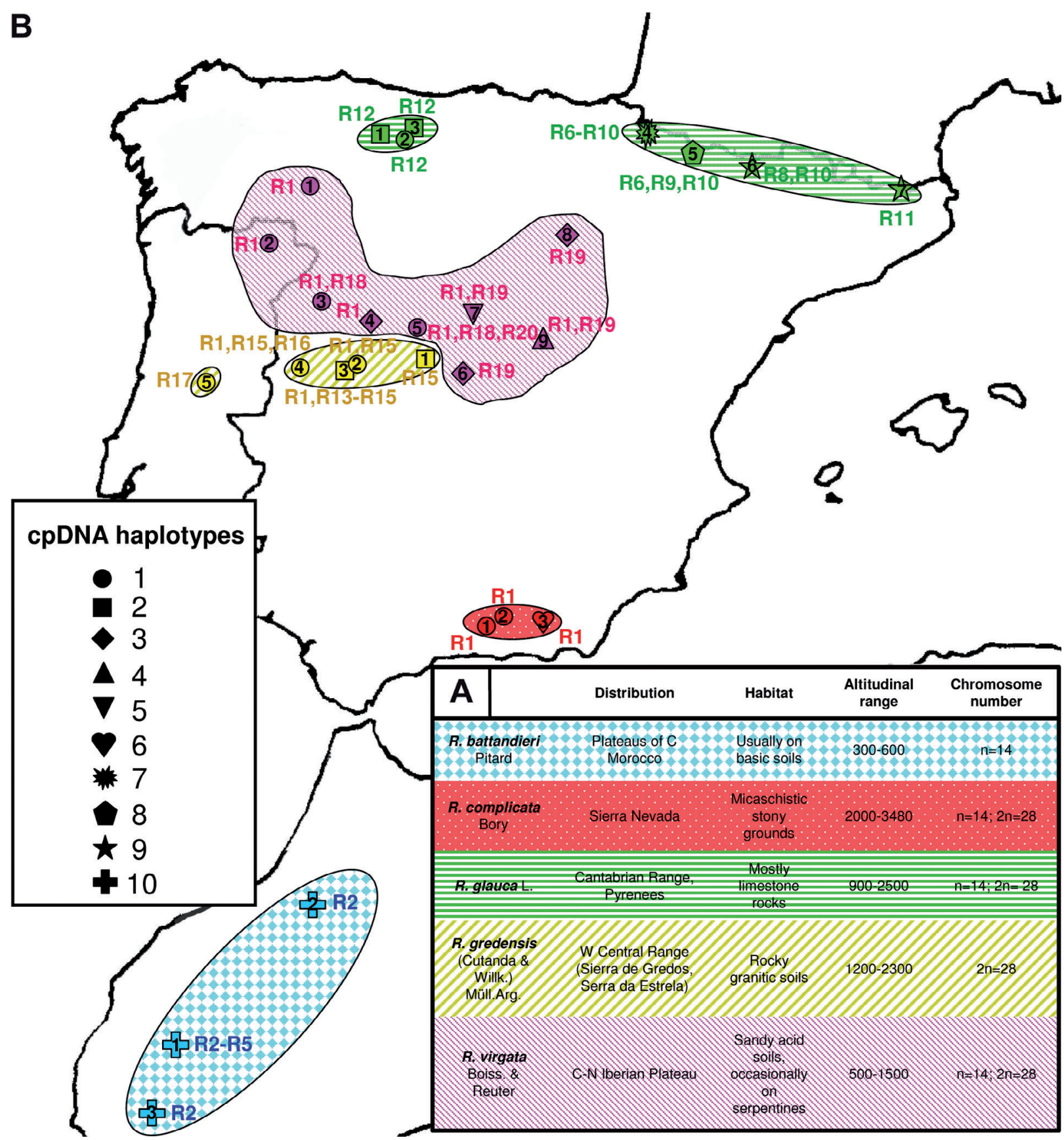

Fig. 1. A, Summary of major characteristics of the five species of Reseda sect. Glaucoreseda, indicating specific distribution, habitat, altitudinal range and chromosome number; B, distributional map of species and samples. Coloured areas indicate approximate distribution of species; numbers preceded by "R" indicate ITS ribotypes (R1-R20); symbols represent $t r n L-F-r p s 16$ haplotypes; and numbers inside symbols indicate population number. Each species is represented by a different colour according to the table in Fig. 1A. 
by altitudinal shifts (Gómez \& Lunt, 2007). The presence of the Moroccan endemic $R$. battandieri within the otherwise Iberian Glaucoreseda is an example of the biogeographical affinities between the Iberian Peninsula and NW Africa (Médail \& Quézel, 1997). About 75\% of the species of the Iberian Mediterranean flora is shared with northern Morocco, with more than 500 Ibero-North African endemic species reported from this disjunct area (Valdés, 1991). Both regions were in contact, allowing exchange between their floras, during the Messinian salinity crisis, from the end of the Miocene to the beginning of the Pliocene (ca. 6.5-5.3 million years ago, Ma; Rodríguez-Sánchez \& al., 2008), due to the partial dessication of the Mediterranean sea as a result of an increased aridity. Glaucoreseda is the only group of the family (ca. 85 species) exclusively composed of mountain or plateau species, whereas most Resedaceae occur in arid areas and at low or colline altitudes. In addition, while Resedaceae are mainly basophilous (Abdallah \& de Wit, 1978), species of Glaucoreseda are found on a variety of substrates (Fig. 1A), ranging from granites $(R$. gredensis) or micaschists (R. complicata) to limestone rocks (R. glauca) and serpentines (some populations of $R$. virgata).

Glaucoreseda is a well-supported monophyletic group, as revealed by a previous molecular phylogeny of the family Resedaceae (Martín-Bravo \& al., 2007). In congruence, the section is well defined by a number of morphological characteristics (four carpels, forked placenta, entire leaves frequently with basal teeth, persistent sepals and stamens). Taxonomic differentiation between the species is also clear (Abdallah \& de Wit, 1978; Valdés Bermejo, 1993). From a cytogenetic point of view, $x=$ 7 was proposed as the basic chromosome number of the section (González Aguilera \& al., 1980), suggesting a tetraploid condition for extant species, which share the same chromosome number $(n=14,2 n=28$; Fig. 1A). Based on these data, González Aguilera \& al. (1980) proposed a vicariance scenario for the origin of the section, which involved the polyploidisation of an ancestral diploid species followed by Quaternary interglacial range fragmentation and allopatric speciation. Previous molecular studies revealed a poor internal resolution of Glaucoreseda, which was linked to a low level of sequence divergence, and tentatively related to the intervention of recent, on-going processes of allopatric speciation (Martín-Bravo \& al., 2007).

Another interesting background resulting from the previous phylogeny of the family was the detection of clear nucleotide additivities or polymorphic sites (positions containing double nucleotide peaks, PS hereafter) in some ITS chromatograms of Glaucoreseda. The presence of multiple ITS copies (i.e., ribotypes) was suggested as the most probable explanation for the PS (Martín-Bravo \& al., 2007). Numerous systematic studies of plants using nrDNA as a molecular marker have faced the problem of heterogeneous ITS sequences (e.g., Sang \& al., 1995; Fuertes Aguilar \& Nieto Feliner, 2003; Escudero \& al., 2008; among others). ITS sequence heterogeneity has frequently been interpreted as a result of hybridisation events and subsequent incomplete concerted evolution. However, few studies have used cloning techniques to evaluate the hybrid origin of ITS intraindividual polymorphims (e.g., Noyes, 2006; Suárez-Santiago $\&$ al., 2007). This is partly due to particularities of cloning, which is costly, considerably time-consuming, and requires the sequencing of several clones for each PCR product to minimise polymerase-replications errors (Zhang \& Hewitt, 2003). Therefore, some researchers have opted to employ the statistical approach of haplotype substraction (Clark, 1990), which infers coexisting ITS copies (i.e., ribotypes) by comparison with sequences with no additivities (Albaladejo \& al., 2005; Segarra-Moragues \& al., 2007b; Jones \& al., 2008). Although it is conceivable that this method generates artificial ribotypes, its accuracy has not been evaluated. The detailed study of ITS intra-individual polymorphism can help to understand important evolutionary processes such as reticulation and genetic divergence of infraspecific lineages or closely-related species.

The monophyly of the section, together with the allopatric distribution of the species in different mountain ranges and plateaus, along with the ITS additivity patterns detected, may indicate that range shifts or dispersal could have played an important role in the evolution and speciation of the section. Our main objective is to study the evolutionary history of Glaucoreseda by analysing molecular divergence within a geographical and temporal well-defined scenario. Particularly, the nuclear ribosomal ITS and four plastid regions ( $r c b L$, matK, rps 16, trnL-F) were sequenced and analysed to address the following specific issues: (1) to evaluate the species monophyly and their phylogenetic relationships within the section; (2) to infer the historical range dynamics and colonisation patterns involved in the evolution of Glaucoreseda; (3) to estimate the divergence time of Glaucoreseda and to relate it to the onset of Quaternary climatic oscillations; and (4) to elucidate the mechanisms involved in the origin of ITS intra-individual polymorphisms.

\section{MATERIALS AND METHODS}

Sampling, DNA extraction, amplification and sequencing. - A total of 27 populations and 102 sequences of the five species of Glaucoreseda were included in the phylogenetic and phylogeographic analyses, based on nuclear ITS and plastid trnL-F-rps16 sequences (Appendix S1 in the Electronic Supplement to this article). The number of populations sampled per species ranged between three ( $R$. battandieri, $R$. complicata) and nine (R. virgata), representing the species distribution in each case (Fig. 1B). Eight populations and 24 sequences of three species of Oligomeris (O. dregeana (Müll. Arg.) Müll. Arg., O. dipetala (Ait.) Turcz., O. linifolia (Vahl) J.F. Macbr.), the sister-group of Glaucoreseda based on a previous molecular phylogeny of the family (Martín-Bravo \& al., 2007), were included as outgroup in the phylogenetic analyses. Forty sequences (17 ITS, 13 trnL-F, 10 rpsl6), obtained in previous molecular studies of Resedaceae (Martín-Bravo \& al., 2007, 2009), were taken from GenBank for the phylogenetic analyses. Total genomic DNA was extracted from silica-dried material collected in the field and herbarium specimens (ARAN, M, MA, SALA, UPOS), using the DNeasy Plant Mini Kit (Qiagen, California, U.S.A.).

The ITS matrix used for the molecular clock analyses was composed of 35 sequences, of which 14 belonged to 
Glaucoreseda, 10 to the rest of the Resedaceae, and 11 to allied taxa of Brassicales (Appendix S1 in the Electronic Supplement). The plastid combined $r b c L$-matK-trnL-F matrix used for the estimation of divergence times of Glaucoreseda included 46 sequences from Glaucoreseda (16 rbcL, 14 matK, $16 \mathrm{trnL}-F$ ), 28 from the rest of the Resedaceae ( $10 \mathrm{rbcL}, 8 \mathrm{matK}, 10 \mathrm{trnL}-F)$ and 49 from other Brassicales (17 rbcL, 17 matK, 15 trnL-F) (Appendix S1 in the Electronic Supplement). Amplification and sequencing of the ITS and plastid $r b c L-m a t K-t r n L-F-r p s 16$ regions were performed following the protocols described in previous molecular studies of the Resedaceae (Martín-Bravo $\&$ al., 2007, 2009).

ITS cloning. - The origin of intra-individual ITS polymorphisms was inferred by the methods of cloning and by ribotype substraction from additive polymorphic sites (APS: the two bases involved in the polymorphism are also found in the other accessions; Wichman \& al., 2002; Fuertes Aguilar \& Nieto Feliner, 2003; Nieto Feliner \& al., 2004). ITS region was cloned in six individuals, one or two for each species showing PS (4 species; Table 1). On the other hand, haplotype substraction was used to infer ribotypes for all individuals (ten) with APS. This method has been used to infer the two putative parental ribotypes involved in an additive sequence. One of them is selected between the sequences with no additivities provided it has one of the two nucleotides responsible for the additivity in all the APS. This sequence is subsequently used as reference for inferring ("substracting") the complementary combination of nucleotides in the APS as the other parental ribotype (Albaladejo \& al., 2005). Accuracy of the haplotype substraction method was evaluated by comparison of the ribotypes inferred by substraction with the ones detected by cloning.

To facilitate cloning, PCR purified products were incubated at $70^{\circ} \mathrm{C}$ for 30 min with $\mathrm{Taq}$ polymerase to provide poli-A tails to the PCR products. These were subsequently ligated into the pGEM-T Easy vector system (Promega, Madison, Wisconsin, U.S.A.) and cloned in DH5- $\alpha$ E. coli competent cells. Positive colonies were grown overnight in liquid cultures and then plasmid isolated with a standard alkaline lysis protocol. Plasmid insertions were amplified and sequenced using standard conditions and original ITS or vector primers SP6 and T7. Eight clones per individual were sequenced to increase the possibility of sampling ITS copies represented in lower proportion, adding up to a total of 48 sequenced clones. We repeated amplification and sequencing of all samples to be cloned and of one clone per individual to minimise the possibility of PCR and sequencing artifacts.

When sequencing clones, we did not consider point mutations appearing in a single clone and for which no variation was observed in the corresponding nucleotide in direct sequences, since they are probably the result of $T a q$ polymerase errors. On the other hand, mutations shared by more than one clone and single point mutations detected in variable positions were considered, assuming the low probability of their being the result of mistakes during replication (e.g., Wichman \& al., 2002).

The structural integrity and potential functionality of clone sequences was evaluated by comparing their length variation, substitution patterns and guanine plus cytosine $(\mathrm{G}+\mathrm{C})$ content
(Grimm \& Denk, 2008). We also searched for the presence of the highly conserved angiosperm motifs GGCRY-(4 to 7n)GYGYCAAGGAA in the ITS1 spacer (Liu \& Schardl, 1994; Rosselló \& al., 2007) and GAATTGCAGAATCC in the 5.8S ribosomal gene (Jobes \& Thien, 1997).

Phylogenetic and haplotype data analyses. - The ITS matrix included 56 sequences (48 corresponding to Glaucoresed $a$ and 8 to the outgroup), of which 24 were obtained by direct sequencing, 22 by cloning and 10 by substraction from APS, whereas the plastid trnL-F-rps 16 matrix was composed of 35 sequences (27 corresponding to Glaucoreseda and 8 to the outgroup). Both matrices were manually aligned and analysed using the programs PAUP* v.4.0b10 (Swofford 2002) and TNT v.1.0 (Goloboff \& al., 2003) for Maximum Parsimony (MP) and MrBayes v.3.0b4 (Ronquist \& Huelsenbeck, 2003) for Bayesian Inference (BI). Parameters used for these analyses (except for TNT, see below), followed those described in Martín-Bravo \& al. (2007). Gaps were treated either as missing data or coded as additional characters in different analyses, with the exception of the highly homoplasic mononucleotide repeat units (poli-T and poli-A; Kelchner, 2000). Congruence of nuclear and plastid datasets was assessed using the Hompart test for matrices (100 replicates) and the Kishino-Hasegawa $(\mathrm{KH})$ and Shimodaira-Hasegawa (SH) tests for tree topology (1000 replicates each), as implemented in PAUP. When the Hierarchical Likelihood Ratio test and the Akaike Information Criterion selected different models of sequence evolution, we implemented that model determined by Akaike, following the recommendations of Posada \& Buckley (2004). When analysing matrices with coded indels, we selected F81 as the model for the corresponding additional characters, following the manual of MrBayes (Ronquist \& Huelsenbeck, 2003). TNT heuristic searches were replicated 10,000 times retaining a maximum of two most-parsimonious trees in each replicate, followed by a second heuristic search retaining all best trees and using the trees obtained in the first 10,000 replicates as the starting ones.

Statistical parsimony analyses of haplotypes were applied to the ITS and plastid trnL-F-rps16 matrices with the program TCS v.1.21 (Clement \& al., 2000), with a 95\% parsimony connection limit. To assess the effect of the inclusion of substracted/cloned ribotypes in the ITS network, two different analyses were performed, including and excluding substracted/ cloned ribotypes (56 and 24 ITS sequences, respectively).

Estimation of divergence times. - We inferred divergence times of Resedaceae and Glaucoreseda by applying the Penalized Likelihood approach to one nuclear (ITS) and one combined plastid (rbcL-matK-trnL-F) dataset. These analyses were based on tree topologies and branch lengths obtained from BI phylogenetic analyses and were performed with the program r8s v.1.71 (Sanderson, 2004), as described in Martín-Bravo \& al. (2009). Recently, the first macrofossil records for the Resedaceae and allied taxa (Gyrostemonaceae, Pentadiplandraceae, Tovariaceae, Forchhammeria) have been reported from Palaeocene formations (62 Ma; Iglesias \& al., 2008). This fossil and the divergence ages between several Brassicales families estimated from molecular and fossil data (Wikström \& al., 2001), were used as calibration points (Fig. 2). 


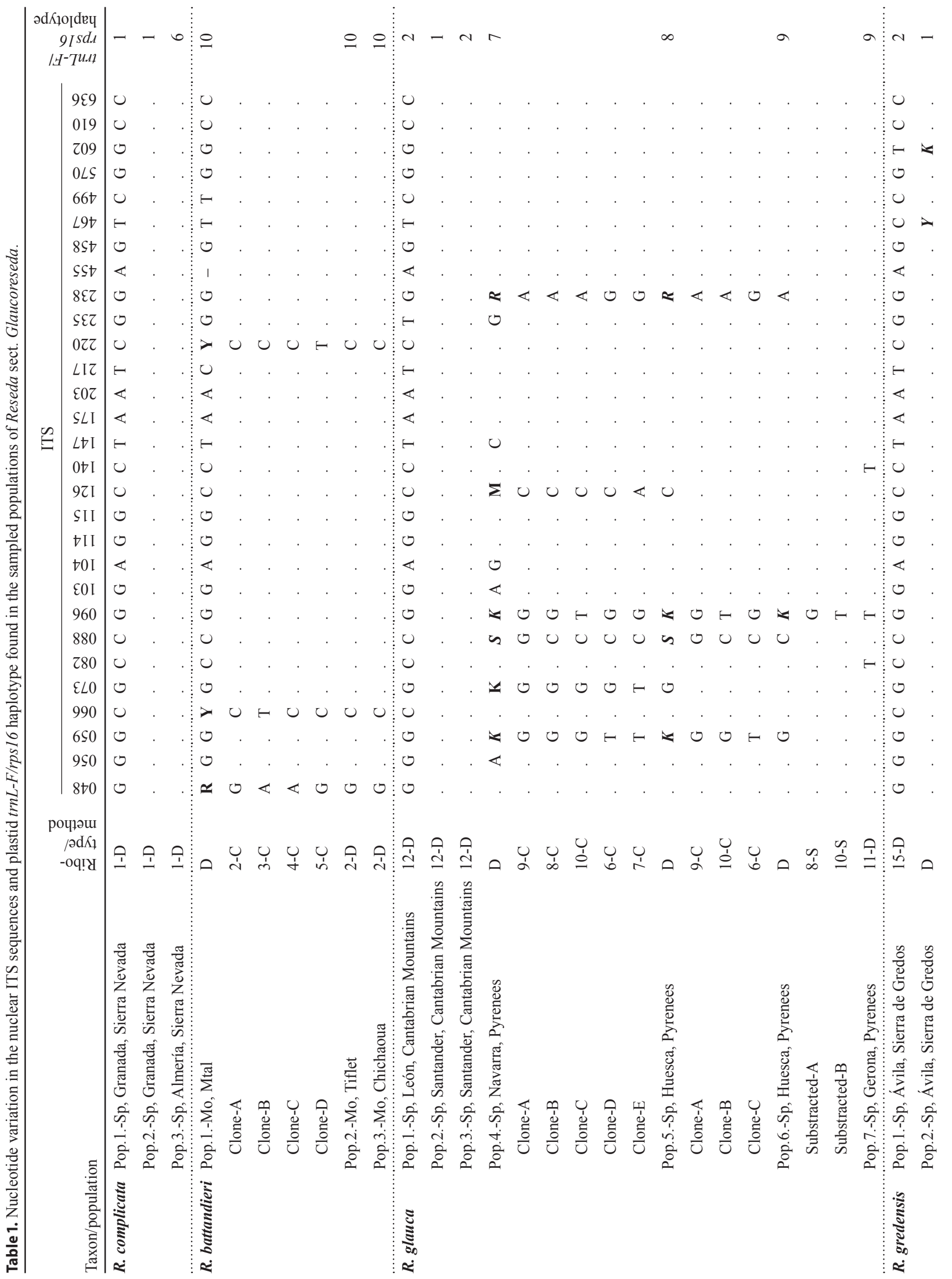




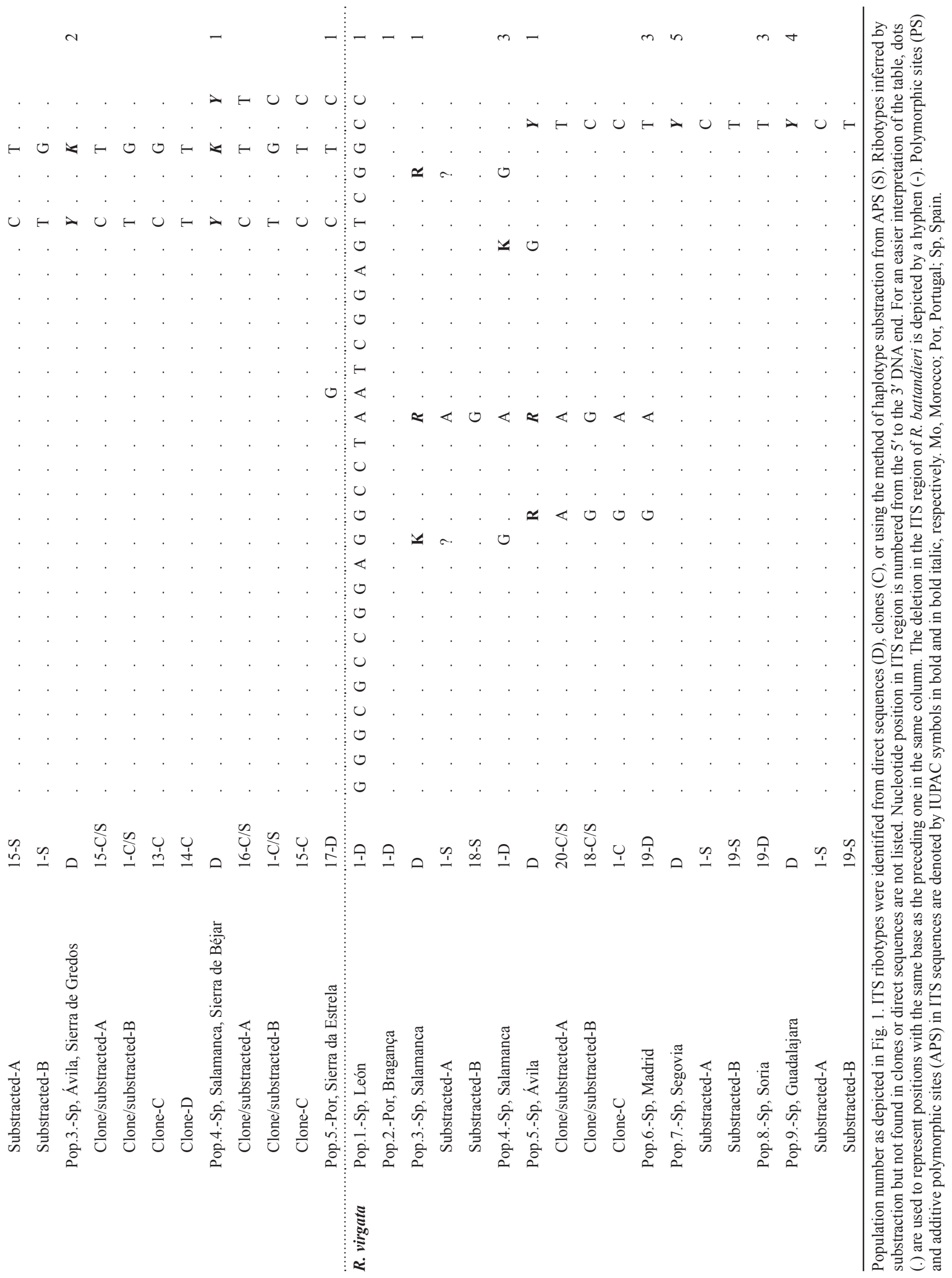




\section{A) ITS}

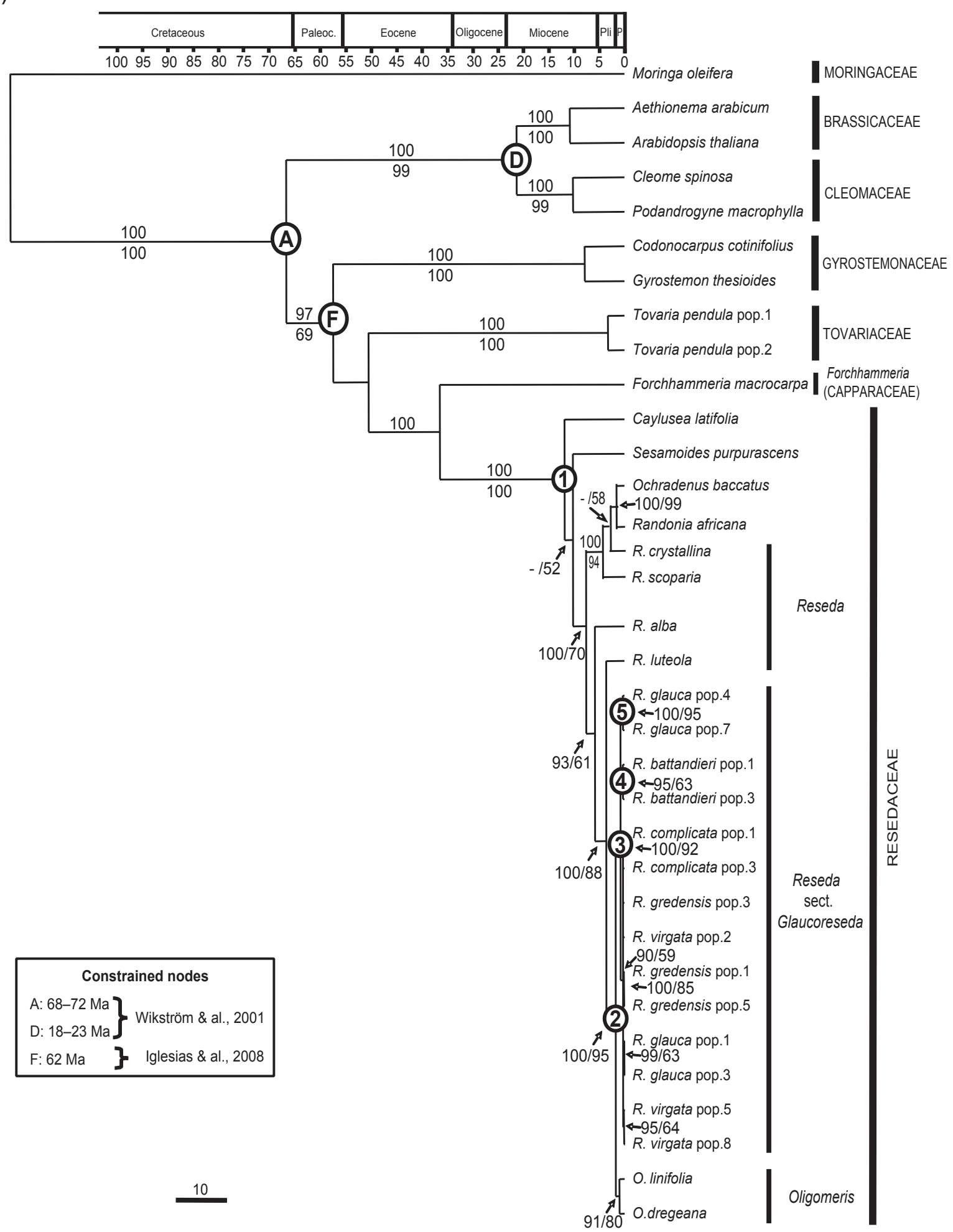

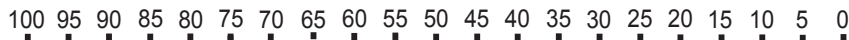

Cretaceous

Paleoc. Eocene

Oligocene Miocene

Fig. 2. Chronograms of Bayesian Inference trees based on the Penalized Likelihood analysis of nuclear ITS (A) and plastid $r b c L-m a t K-t r n L-F$ (B) sequences. Branch lengths represent million years ago (Ma). Posterior probabilities and bootstrap values are given above and below branches, respectively. Vertical bars indicate supraspecific taxa from the same taxonomic group. Maximum and minimum ages of the nodes used to 


\section{B) rbcL-matK-trnL-F}

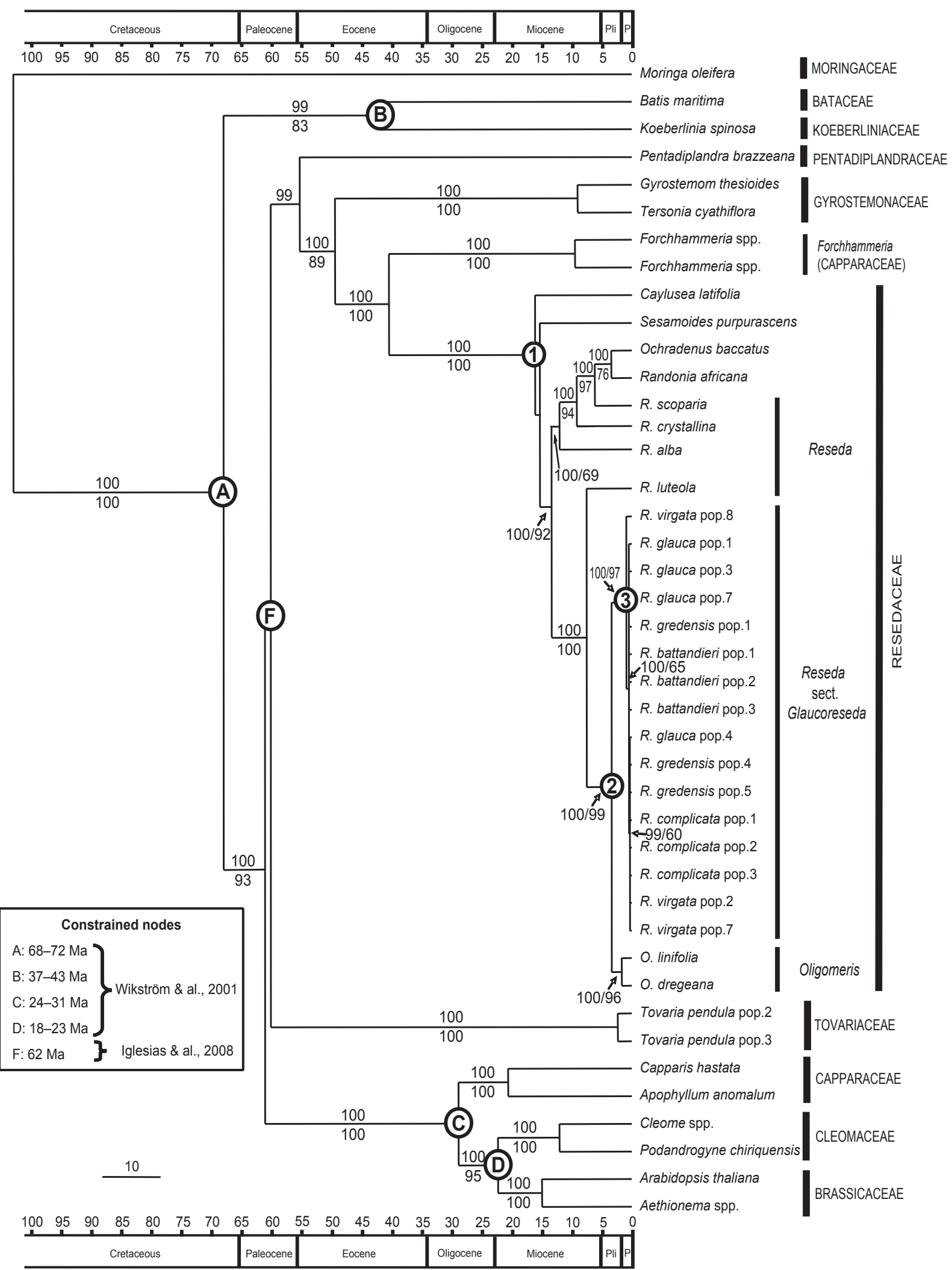

constrain divergence times between different lineages within the Brassicales are shown within boxes for each of the two chronograms, and represented by letters on the trees (A-F). Numbers (1-5) indicate nodes whose age was estimated (see Table 2). P, Pleistocene; Paleoc., Paleocene; Pli, Pliocene. 
The analyses were repeated using an older estimate for the origin of the Brassicaceae (50 Ma; Koch \& al., 2001; Al-Shehbaz $\&$ al., 2006). The null hypothesis of constancy of substitution rates (molecular clock) was rejected for both datasets. The best smoothing parameter obtained with the Penalized Likelihood method was 3.2 for the ITS and 32 for the plastid dataset. Due to the low level of sequence divergence in Glaucoreseda, we used a subset of populations (18) in the Penalized Likelihood analyses, representing the distribution of the five species and the sequence diversity found in our sampling, with at least three accessions per species.

\section{Q RESULTS}

ITS sequencing and ribotypes. - In Glaucoreseda, the ITS region was $637-638$ base pairs (bp), with a variable to parsimony-informative sites ratio of 28/16 for the whole ITS region ( $21 / 12$ for ITS1, $0 / 0$ for $5.8 \mathrm{~S}$ and $7 / 4$ for ITS-2). Only one informative indel was found and coded $(R$. battandieri, $1 \mathrm{bp}$ long). Thirty PS were detected in 12 of 27 accessions (one to six PS per sequence), and distributed in all species of the section except $R$. complicata (Table 1). Twenty of the PS were APS (one to four per accession).

Ribosomal sequence integrity suggests that all clones are functional ITS copies, except for one highly divergent clone of $R$. gredensis (pop. 4), characterised by a decreased $\mathrm{G}+\mathrm{C}$ content with respect to the rest of the clones $(53.7 \%$ vs. mean $56.4 \%)$, increased mean K2P pairwise genetic distances $(4.49 \%$ vs. $1.42 \%$ ), and reduced sequence length due to deletions in the ITS1 spacer and 5.8S region (456 bp. vs. 637-638bp). This anomalous clone also lacked the conserved ITS1 motif of Liu \& Schardl (1994) and showed two mutations in the conserved 5.8S motif (Jobes \& Thien, 1997). Therefore this copy is probably a pseudogene, and was subsequently excluded from the analyses.

The application of the three different methods (direct sequencing, cloning, substraction from APS) revealed a total of 20 different Glaucoreseda ribotypes (R1-R20; Table 1), of which seven were detected in direct ITS sequences (R1, R2, R11, R12, R15, R17, R19). Sixteen different ribotypes were retrieved from clones, of which seven were also found by substraction and three by direct sequencing (Table 1). Substraction from the ten individuals with APS yielded ten different ribotypes. Direct or cloned sequences matched eight of the ten substracted ribotypes, and the two putative parental ribotypes for eight of the ten individuals with APS (Table 1). For the remaining two individuals with APS (R. glauca pops. 4 and 5) the same two putative parental ribotypes were inferred by substraction; however none of them were found in direct or cloned sequences. These two ribotypes were subsequently excluded from the analyses, as they could be artefacts of the substraction method. Eight ribotypes exclusively detected in cloned sequences were identified as putative recombinants and/or rare ITS copies not apparent in direct sequences. Ribotypes found in clones and direct sequences explained all the PS (21) found in the six ITS cloned sequences. The number of ribotypes per species ranged between one ( $R$. complicata) and seven ( $R$. glauca)
The number of ribotypes found in the six cloned samples varied between three ( $R$. glauca pop. 5, R. gredensis pop. 4, $R$. virgata pop. 5) and five (R. glauca pop. 4).

Phylogeographic analysis of ITS ribotypes. - A single ribotype network was retrieved, including the 20 ribotypes detected (Fig. 3A). Ribotype 1 (R1) was the most common and widespread, spanning the central area of the range of Glaucoreseda (Sierra Nevada, Sierra de Gredos and central-northern plateau; Fig. 1B). It was found in 13 populations belonging to three different Iberian species ( $R$. complicata, R. gredensis, $R$. virgata), and occupied an internal position in the network (Fig. 3A). It was the one with more mutational connections (six) and the only shared ribotype between different species. Ribotypes found in the Moroccan endemic $R$. battandieri (four, R2-R5) and Pyrenean populations of R. glauca (six, R6-R11) appear clearly segregated in the network (Fig. 3A), in congruence with its placement in the ITS phylogenetic tree (Fig. 4A). Conspecific $R$. glauca populations from the Cantabrian Mountains showed a single ribotype (R12), which was differentiated by only one mutational step from the central R1, due to a single substitution (Table 1). Finally, five additional species-specific ribotypes were detected for $R$. gredensis (R13-R17), and three for $R$. virgata (R18-R20), which differed by no more than three substitutions from R1. The inclusion of cloned and substracted ribotypes did not substantially affect the topology of the network constructed with the seven ribotypes found within direct sequences (not shown). Coding of the single indel found in $R$. battandieri did not have a strong effect on the ITS network topology, as it introduced only one additional mutation step between $R$. battandieri and R1 (Fig. 3A).

Phylogeographic analysis of plastid haplotypes. - Plastid sequence lengths in Glaucoresed $a$ varied between 720 and $729 \mathrm{bp}$ for trnL-F and between 821 and $839 \mathrm{bp}$ for $r p s 16$, with a ratio of variable to parsimony-informative sites of $8 / 4$. Three indels of 7-11 bp were detected and coded, one of them shared by all populations of $R$. battandieri, while the remaining two were exclusive to $R$. virgata (pops. 7 and 9 each). Nine variable sites were observed within the $16 \mathrm{rbcL}$ and $14 \mathrm{mat} K$ accessions of Glaucoreseda used for the molecular clock analyses, of which none was parsimony informative.

When analysing the plastid trnL-F-rps16 sequences with indels coded, ten different haplotypes were identified (H1H10). The pattern of genealogical relationships between plastid haplotypes depicted by TCS (Fig. 3B) was similar to that retrieved from ITS sequences (Fig. 3A). The most frequent haplotypes (H1, H2), distributed throughout the central area of the range of Glaucoreseda (Sierra Nevada, Sierra de Gredos, Serra da Estrela, central-northern plateau and Cantabrian Mountains), are shared between different species and are positioned as internal nodes in the network (Fig. 3B). In addition, H1 and $\mathrm{H} 2$, which only differed by one substitution, showed the highest number of mutational connections (four and six, respectively; Fig. 3B). Haplotype 1 was found in ten populations representing all species of Glaucoreseda except $R$. battandieri, whereas $\mathrm{H} 2$ was only shared by $R$. gredensis and Cantabrian R. glauca, two populations each. Four species-specific haplotypes were found in five populations of $R$. virgata $(\mathrm{H} 3, \mathrm{H} 4, \mathrm{H} 5)$ and the 
eastern-most population of $R$. complicata (H6). Pyrenean populations of R. glauca possess three exclusive haplotypes $(\mathrm{H} 7, \mathrm{H} 8$, H9) which differed by one mutation from $\mathrm{H} 1$ or H2 (Fig. 3B). Finally, the three populations of $R$. battandieri showed a single haplotype (H10), which was separated by two mutations from H2 (Fig. 3B). When indels were not coded, the only difference was that $\mathrm{H} 5$ from $R$. virgata was not retrieved (not shown).

Phylogenetic analyses. - Maximum Parsimony analyses of the ITS matrix (aligned length $638 \mathrm{bp}$, two coded indels) retained twelve best trees with 54 steps (consistency index, $\mathrm{CI}=0.94$; retention index, $\mathrm{RI}=0.99$; rescaled consistency index, $\mathrm{RC}=0.95$; results not shown). The MP analysis of the plastid trnL-F-rps16 matrix (aligned length $1608 \mathrm{bp}$, eight coded indels) produced a single tree of 38 steps $(\mathrm{CI}=1, \mathrm{RI}=$ $1, \mathrm{RC}=1$; not shown). Phylogenetic reconstructions of nuclear and plastid matrices retrieved significantly different topologies (Fig. 4; KH and SH tests, $P \leq 0.036$ ) and the Hompart test showed that both datasets were partially incongruent $(P=0.04$ when testing the whole matrices, $P=0.02$ when excluding the outgroup). Therefore, we did not perform phylogenetic analyses for a combined ITS-trnL-F-rps 16 matrix. Bayesian Inference analyses were performed using the K80 evolutionary model for the ITS- 1 and the GTR + I for the ITS-2 spacer (5.8S region was constant and therefore was excluded from analyses), whereas GTR was used as the simplest model of sequence evolution for the plastid trnL-F-rps 16 matrix. Majority rule consensus trees obtained from the BI analyses of the nuclear and plastid matrices (Fig. 4) were mostly in agreement with the strict consensus trees retrieved from the MP analyses (not shown). The inclusion of indels as additional characters for phylogenetic analyses did not have a significant effect either on the nuclear and plastid tree topologies or on branch supports.

Reseda sect. Glaucoreseda formed a strongly-supported monophyletic group ( $\geq 99 \%$ BS, $100 \%$ pp) in all phylogenetic analyses (Fig. 4), in congruence with previous molecular studies (Martín-Bravo \& al., 2007). The only well-supported monophyletic group in both ITS and plastid phylogenies was R. battandieri ( $\geq 95 \%$ BS, $\geq 99 \%$ pp; Fig. 4). Cantabrian ( $63 \%$ BS, $98 \%$ pp) and Pyrenean (97\% BS, $100 \%$ pp) populations of $R$. glauca clustered in two distinct monophyletic groups in the ITS tree (Fig. 4A), while in the plastid tree they are unresolved in five different lineages (Fig. 4B). Populations of the remaining species ( $R$. complicata, $R$. gredensis, $R$. virgata) appear mostly unresolved, although they formed a poorly-supported clade in the ITS tree (63\% BS; Fig. 4A). The large, basal polytomy and poor internal resolution in plastid and nuclear phylogenies seems to be the result of ribotype/haplotype sharing between accessions and the relatively low level of sequence divergence detected within Glaucoreseda, both for ITS $(0 \%-1.91 \%)$ and trnL-F-rps $16(0 \%-0.19 \%)$ sequences.

Estimation of divergence times. - Divergence times estimated with the Penalized Likelihood analysis for the two different datasets (ITS; $r b c L-m a t K-\operatorname{trn} L-F$ ) were mostly congruent, except for the Glaucoreseda stem node (Table 2). The split of Resedaceae was estimated to have occurred probably during the Miocene (12.06 $\pm 2.77 \mathrm{Ma}$, ITS; $16.10 \pm 1.22 \mathrm{Ma}$, $r b c L-m a t K-t r n L-F$; node 1, Fig. 2; Table 2). These results are in

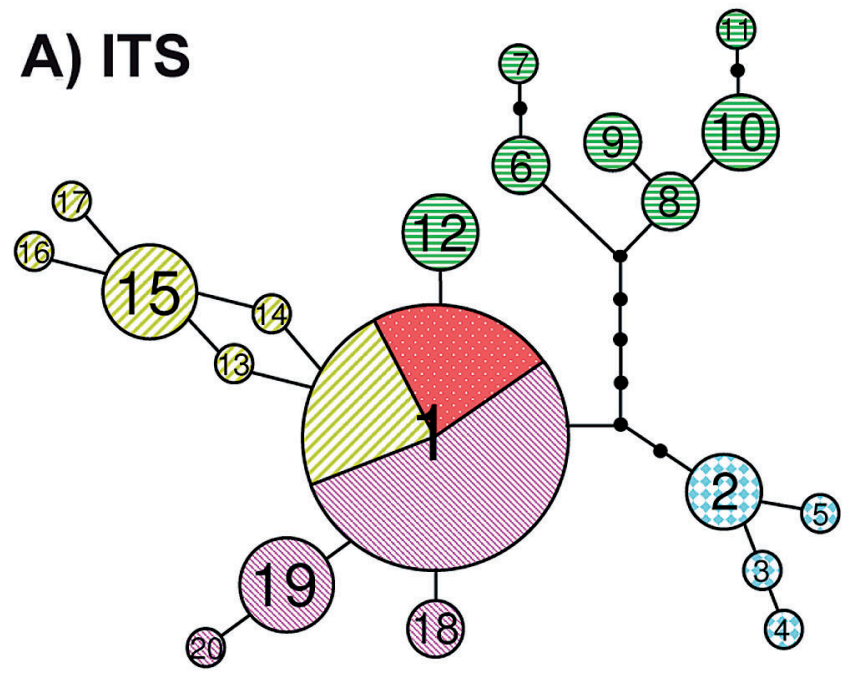

\section{B) $\operatorname{trnL-F-rps16}$}

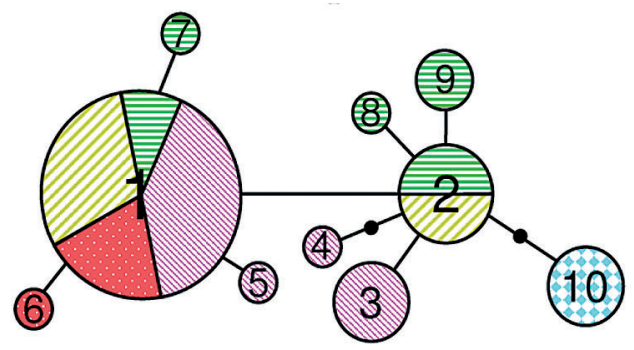

Fig. 3. Statistical parsimony networks depicting genealogical relationships between the five species of Reseda sect. Glaucoreseda, based on ITS (A) and trnL-F-rps16 (B) sequences. Ribotype/haplotype numbers are enclosed in coloured circles and lines connecting them represent mutational changes in the correspondent ITS or trnL-Frps16 sequence. Circle size is proportional to the number of samples displaying the corresponding ribotype/haplotype. Dots represent inferred intermediate ribotypes/haplotypes extinct or not sampled. Colour key used for species identification is as in Fig. 1.

line with the estimates obtained in previous studies which did not take into account the Palaeocene (62 Ma) fossil calibration $(10.48 \pm 1.82 \mathrm{Ma}$, ITS; $12.60 \pm 0.85 \mathrm{Ma}$, cpDNA; Martín-Bravo $\&$ al., 2009), although the inclusion of the fossil constraint slightly increased divergence ages. The stem node of Glaucoreseda (node 2) was placed in the lower Pleistocene (1.62 $\pm 0.79 \mathrm{Ma}$, ITS; Fig. 2A) or in the Pliocene ( $2.98 \pm 0.76 \mathrm{Ma}$, cpDNA; Fig. 2B). The crown node of Glaucoreseda (node 3) fell at the beginning of the Middle Pleistocene $(0.73 \pm 0.45 \mathrm{Ma}$, ITS; $0.60 \pm 0.48 \mathrm{Ma}$, cpDNA). We also obtained time estimates, based on the ITS chronogram, for the split of $R$. battandier $i$ $(0.29 \pm 0.40 \mathrm{Ma}$; node 4, Fig. 2A; Table 2) and the Pyrenean populations of $R$. glauca $(0.26 \pm 0.29 \mathrm{Ma}$; node 5, Fig. 2A; Table 2). These nodes were not resolved in the plastid chronogram (Fig. 2B) so the correspondent split times could not be 

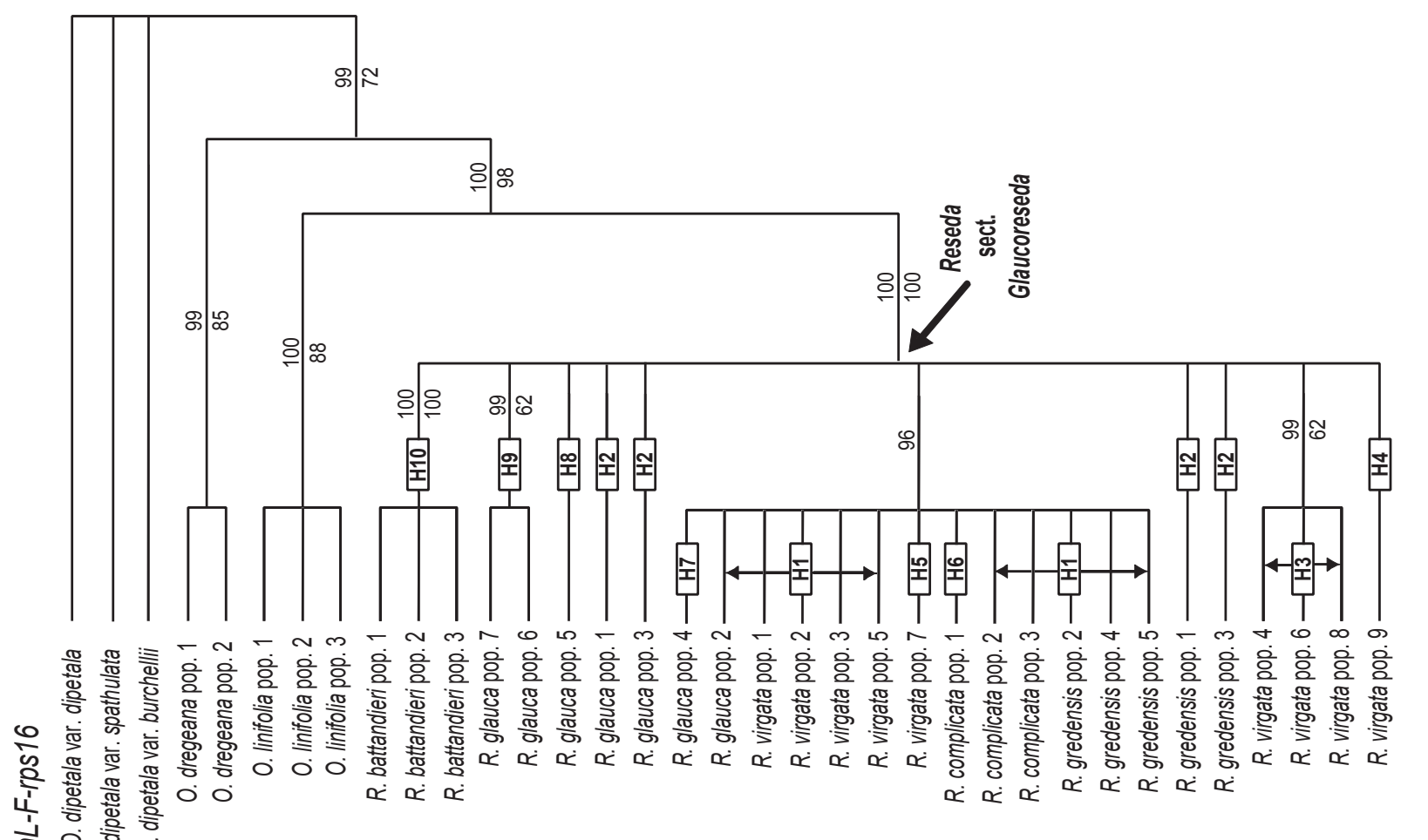

空
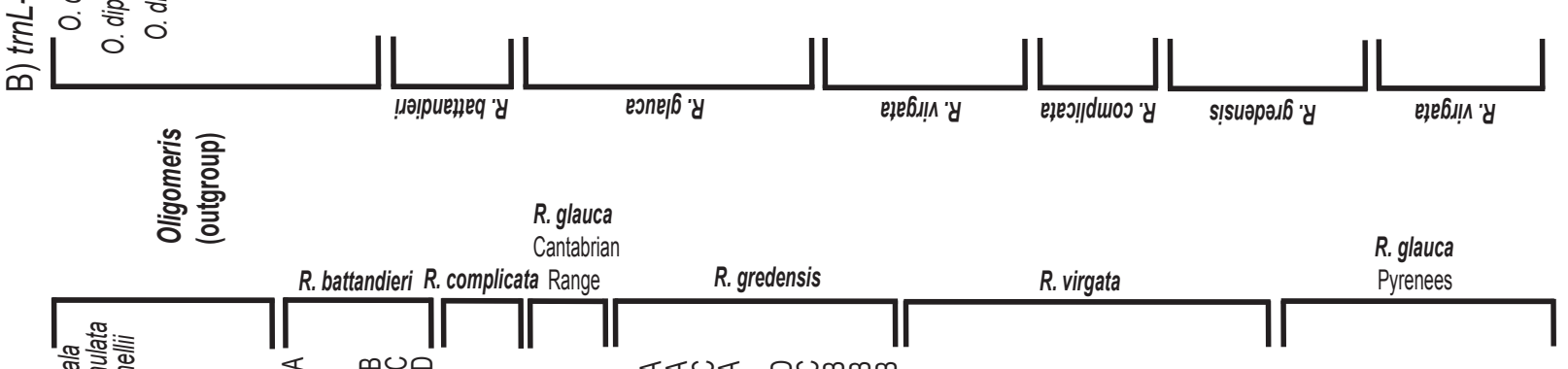

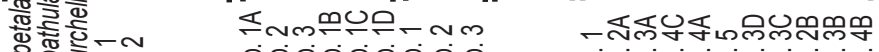

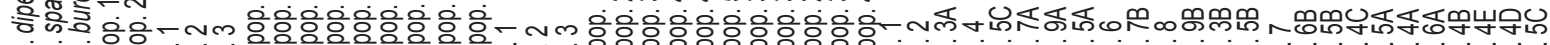

市 市 $\frac{2}{\pi}$ 응

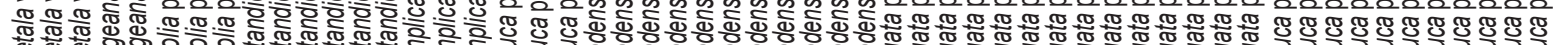

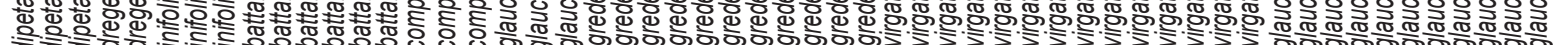

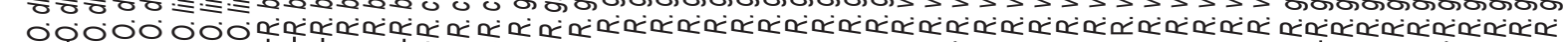

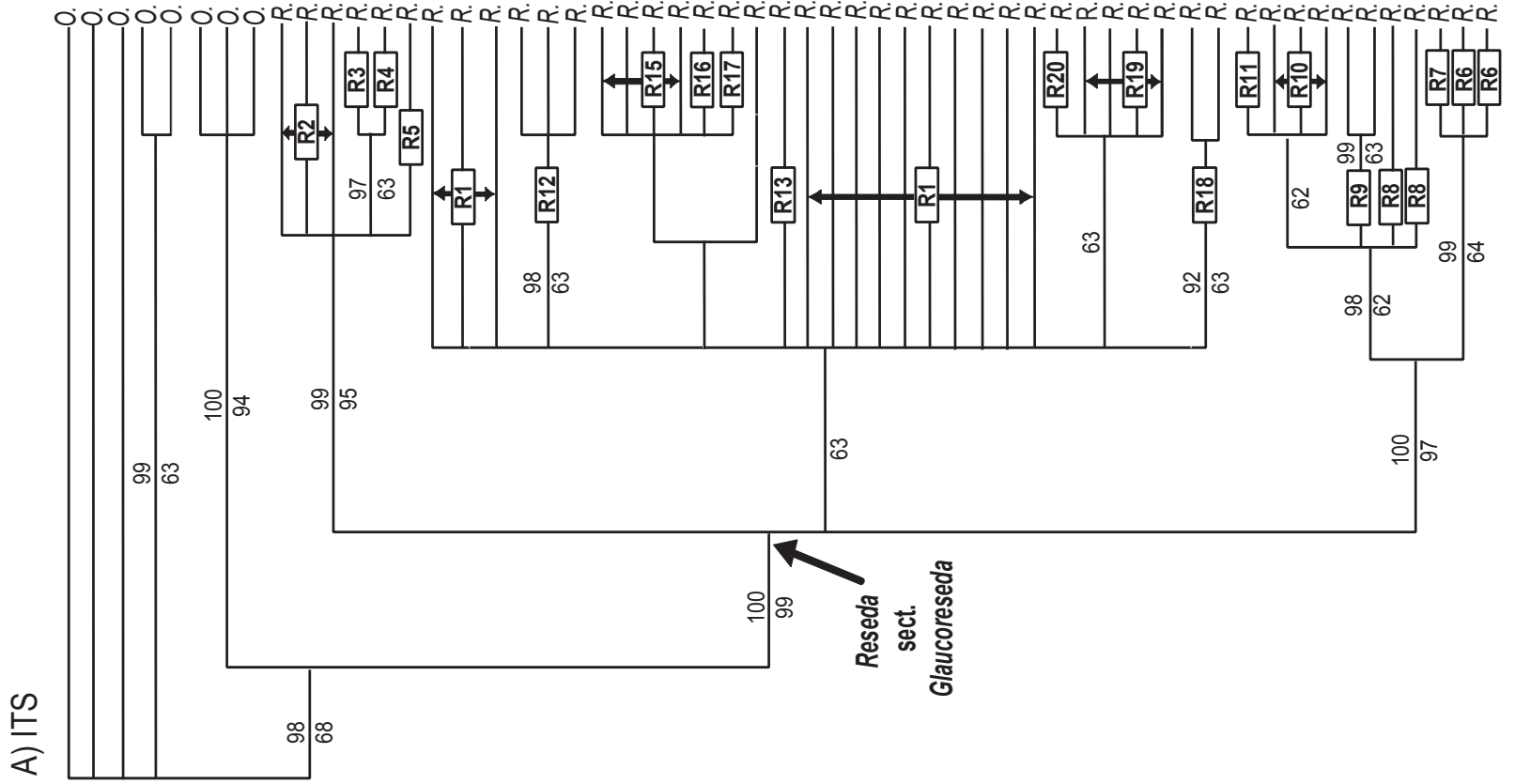

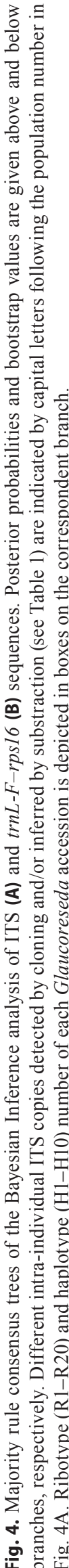


Table 2. Penalized Likelihood age estimates (mean, standard deviation, minimum and maximum) for the most important unconstrained nodes in the Resedaceae and in Reseda sect. Glaucoreseda, based on the analysis of two matrices (ITS, rbcL-matK-trnL-F).

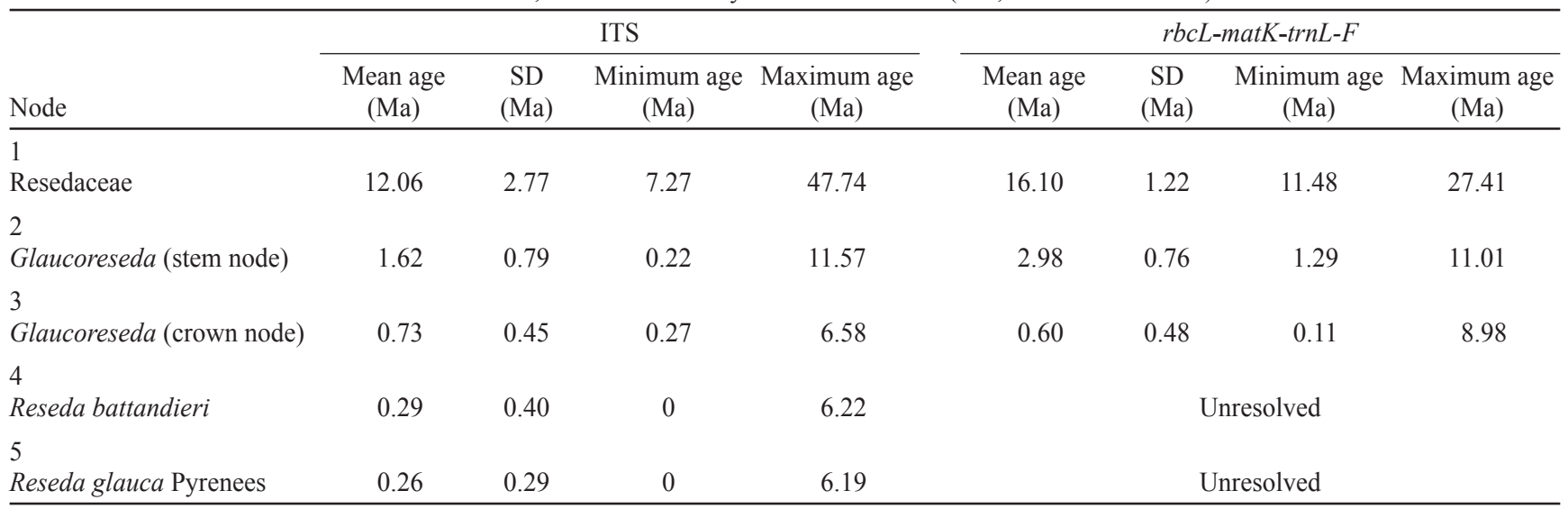

Nodes numbered as in Fig. 2. Ma = million years ago; $\mathrm{SD}=$ standard deviation.

worked out. Results obtained when using the oldest estimate of divergence time for Brassicaceae (Koch \& al., 2001; AlShehbaz \& al., 2006) as calibration point were very similar (results not shown).

\section{DISCUSSION}

Nuclear ribosomal ITS diversity. - Ribotypes retrieved from clones accounted for all PS encountered in the correspondent direct ITS sequences and for most ribotypes inferred by substraction from APS (Table 1). However, ITS copies are not always detected by direct sequencing or substraction if they are in low proportion, as revealed by the finding of eight exclusive ribotypes in the cloned sequences $(40 \%$ of the total number of ribotypes found). Thus, an important proportion of intragenomic polymorphisms may remain unnoticed in direct ITS sequences and the number of different copies may be underestimated by substraction (Gernandt \& al., 2001; Nieto Feliner \& al., 2004; Rosselló \& al., 2007). In addition, some putatively recombinant ribotypes were also identified in the clones, although the possibility of in vitro PCR recombination or in vivo partial homogenisation cannot be ruled out (Rosselló $\&$ al., 2007). Two of ten ribotypes inferred by substraction $(20 \%)$ were not detected by cloning or direct sequencing (Table 1). This fact could be due to insufficient clone sampling, recombination, or biased concerted evolution towards one of the parental types (Fuertes Aguilar \& Nieto Feliner, 2003). Therefore, inference of coexisting ribotypes from direct ITS sequences by substraction (Clark, 1990) could be a suitable approach when facing the problem of intra-individual ITS polymorphisms and cloning of all sequences is not possible, provided a putative parental ribotype is detected in the dataset. However, the application of this method is not free of drawbacks as it may generate artificial ribotypes and may overlook the existence of ITS copies in low proportion, especially when ancient hybridisation or reticulation processes are likely or there is a high number of additivities involved.
Discordance between nuclear and cpDNA genealogies and taxonomy. - Congruence tests (Hompart, KH, SH tests) revealed that nuclear and plastid phylogenies were incongruent. In addition, both reconstructions were also partially discordant with taxonomy since one ribotype (R1) and two haplotypes (H1, H2) are shared between different species (Figs. 3, 4). Moreover, coexisting intra-individual ITS copies were detected by cloning. These facts could be related to the intervention of biological processes like recent hybridisation and/or preservation and differential sorting of ancestral polymorphisms (Wendel \& Doyle, 1998).

The incongruent, species-independent ribotype and haplotypes (R1; H1, H2) are the most frequent, occupy internal positions within the parsimony networks and show the highest amount of mutational connections (Fig. 3). On the other hand, haplotypes at the tips of the networks are species-specific and were found at lower frequencies. According to the coalescent theory, the patterns of genealogical relationships depicted by the networks suggest that these incongruent ribotype and haplotypes may be ancestral and probably predating species divergence within Glaucoreseda (Castelloe \& Templeton, 1994; Schaal \& al., 1998; Pleines \& al., 2009). Therefore, incomplete lineage sorting of ancestral ITS and plastid polymorphisms due to recent divergence appears to be more plausible than gene flow between distinct species to explain the incongruence between the two genealogies and taxonomy. Accordingly, neither contact areas nor hybrids between the different species have been described in Glaucoreseda, unlike for other plant groups for which incongruence between nuclear and plastid markers has also been reported (Nieto Feliner \& al., 2004; Albaladejo \& al., 2005; Suárez-Santiago \& al., 2007; Vargas \& al., 2009).

Incomplete lineage sorting should be a more common phenomenon in nuclear than in plastid genomes due to the larger effective population size of the nuclear one (Schaal \& al., 1998). However, this process has been suggested to have influenced the evolution of both plastid (Comes \& Abbott, 2001; Jakob \& Blattner, 2006; Koch \& Matschinger, 2007) and nuclear 
regions, including single-copy genes (Olsen \& Schaal, 1999; Caicedo \& Schaal, 2004) and nuclear ribosomal ITS (Gernandt \& al., 2001; Albaladejo \& al., 2005). Lineage sorting has also been detected even with a hypervariable marker such as AFLPs (Kropf \& al., 2006, 2008), which predominantly comes from the nuclear genome. Therefore, this process is increasingly being reported as one of the main causes of phylogenetic incongruence.

The Moroccan $R$. battandieri was the only monophyletic species both in the ITS and plastid phylogenies (Fig. 4). In the ITS tree, Cantabrian and Pyrenean populations of $R$. glauca clustered in two distinct clades (Fig. 4A), which were not retrieved in the plastid phylogeny (Fig. 4B). The remaining species appear mostly unresolved in phylogenetic trees due to a low level of sequence divergence, which may suggest synchronous processes of allopatric speciation (Martín-Bravo \& al., 2007). However, the lack of monophyletic groups enclosing morphologically well-defined taxa is not always an evidence of non-monophyly (Fuertes Aguilar \& Nieto Feliner, 2003; Suárez-Santiago \& al., 2007). Morphological divergence is sometimes not related to the degree of genetic differentiation, as exemplified by the well-known phenomenon of adaptive radiation (Schaal \& al., 1998). In the case of Glaucoreseda, whose species are morphologically well-differentiated (Abdallah \& de Wit, 1978; Valdés Bermejo, 1993), it appears that the sharing of haplotypes and the relatively high genetic similarity, most likely reflects recent common ancestry rather than gene flow. It is possible that sequence variation did not have enough time to completely sort into distinct species lineages, probably resulting in the lack of phylogenetic resolution (Kropf \& al., 2006, 2008).

Pleistocene evolution of Reseda sect. Glaucoreseda in the Iberian Peninsula. - Our results suggest that speciation within Glaucoreseda in the Iberian Peninsula could be related to range shifts induced by Pleistocene climatic oscillations. Firstly, divergence time estimates calculated with the Penalized Likelihood approach (crown node: $0.73 \pm 0.45 \mathrm{Ma}$, ITS; 0.60 $\pm 0.48 \mathrm{Ma}$, cpDNA; Fig. 2; Table 2) are consistent with a late Pleistocene diversification of Glaucoreseda lineages. On the other hand, the split of Glaucoreseda lineage from its sistergroup Oligomeris (stem node: $1.62 \pm 0.79 \mathrm{Ma}$, ITS; $2.98 \pm 0.76$ Ma, cpDNA; Fig. 2; Table 2) appears to have been related to the start of the global cooling (Lower Pleistocene; c. $1.8 \mathrm{Ma}$ ) but also to the onset of the Mediterranean climate (3.2 Ma; Suc, 1984), considering the standard errors of divergence time estimations.

In addition, incomplete lineage sorting of ancestral ITS and plastid polymorphisms could be explained by relatively recent range fragmentation of an ancestral widespread species. Ancestral cpDNA polymorphisms predating speciation events have been suggested to persist from 0.4 to $4 \mathrm{Ma}$ (Comes \& Abbott, 2001; Jakob \& Blattner, 2006). This hypothesis is consistent with the geographical distribution of the incongruent, putatively ancestral ribotype and haplotypes (R1; H1, H2) across a wide range of the Iberian Peninsula (Fig. 1B). Ancestral haplotypes are expected to be more frequent in or near the area of their geographical origin (Templeton, 1998). Therefore, this pattern may indicate that an ancestral, cold-adapted species could have been more or less continuously distributed in lowlands, as postulated for other European mountain plants (Zhang \& al., 2001; Comes \& Kadereit, 2003; Kropf \& al., 2003, 2006, 2008). During glacial periods, vast medium-altitude areas in the central Iberian Peninsula were covered by cold steppe/ tundra vegetation, providing suitable habitats for mountain plants (Ray \& Adams, 2001). The Pyrenees were the only extensively glaciated range, although patches of permanent ice sheet were also found in other high mountains of the Iberian Peninsula (Hughes \& al., 2006). Interglacial warming probably forced populations to retreat to disjunct, high elevated mountain ranges or plateaus (Kropf \& al., 2008). Allopatric divergence of the resulting isolated populations may have occurred subsequently, leading to current Glaucoreseda endemics. Therefore, vicariance driven by Pleistocene glaciations seems to be the most plausible scenario for the diversification of Glaucoreseda in the Iberian Peninsula, as for some other European mountain plant groups (Zhang \& al., 2001, 2004; Kropf \& al., 2006, 2008). Low genetic differentiation both for ITS and plastid sequences, and lack of complete concerted evolution may be also the result of recent vicariance due to interglacial isolation. Likewise, incomplete lineage sorting has been suggested to be especially likely in recently diverged or rapidly radiating species groups (Pleines \& al., 2009).

Interestingly, while the high-mountain species of Glaucoreseda ( $R$. complicata, $R$. glauca, $R$. gredensis) are perennial, the medium-altitude species $R$. battandieri and $R$. virgata display short life-cycles. This could be interpreted as an adaptation to lower altitudes, where precipitation is often more unpredictable than in high altitude habitats (Silvertown \& Charlesworth, 2001).

The fact that incongruence between genealogy and taxonomy is probably explained by incomplete lineage sorting and not by gene flow leads to the idea that no secondary contacts between Glaucoreseda isolated populations have occurred after the interglacial range fragmentation. Similar cases are documented of old population differentiation in alpine plants without subsequent interferences (Puscas \& al., 2008). It is possible that adaptation to different kinds of substrates in Glaucoreseda (granites in the case of $R$. gredensis, michaschists in $R$. complicata, limestones in $R$. glauca, sandy acid soils or serpentines in $R$. virgata) implied a strong selective pressure that promoted rapid morphological differentiation and the development of reproductive barriers, precluding gene flow between the divergent disjunct populations (Schluter, 1996; Hendry \& al., 2007). Edaphic adaptation has been reported as an important cause driving evolution and ultimately speciation in several plant groups (e.g., Zhang \& al., 2001; Verboom \& al., 2004), including alpine species (Alvarez \& al., 2009). Therefore, ecological specialisation could have acted in concert with geographical isolation to foster rapid speciation in Glaucoreseda in the Iberian Peninsula (Dixon \& al., 2007), as has been suggested for other Resedaceae endemics (Martín-Bravo \& al., 2007).

Interestingly, Pyrenean populations of $R$. glauca appeared separated from conspecific populations from the Cantabrian Mountains in both network reconstructions (Fig. 3). The floras 
of both ranges are closely related, as reflected in the high number of shared endemics (Villar \& Laínz, 1990), including intraspecific differentiation between Cantabrian and Pyrenean lineages (Kropf \& al., 2003). Distinctiveness of Pyrenean populations of $R$. glauca has already been suggested based on isozyme studies (González Aguilera \& al., 1980; González Aguilera \& Fernández Peralta, 1984). In R. glauca, the genetic divergence of Pyrenean populations could be interpreted as evidence of isolation, which according to the ITS-dated phylogeny may have not predated the Middle Pleistocene $(0.26 \pm$ $0.29 \mathrm{Ma}$, Table 2). It is possible that some populations survived the Pleistocene glacial periods in isolated peripheral refugia in the Pyrenees (Segarra-Moragues \& al., 2007a; Dubreuil \& al., 2008). Two facts may indicate that these refugia could have been located in the western, lower-altitude Pyrenees (Zhang \& al., 2001), from which a westward recolonisation of the chain could have taken place. Firstly, a pattern of genetic diversity decreasing from the west to the east of the Pyrenees is inferred from ITS ribotypes (Table 1). Thus, the western-most population (pop. 4) was the one with the highest amount of different ITS ribotypes found by cloning (five, R6-R10). The number of ribotypes was decreasing to the east (three in pop. 5; two in pop. 6), with only one ribotype (R11) observed for the eastern-most accession (pop. 7). Glacial refugia have usually been considered as harbours of higher levels of genetic diversity due to long-term persistence, whereas the recolonisation of new territories usually implies a loss of genetic variation as a result of successive founder effects (i.e., Hewitt, 2000). Secondly, the tip position of the eastern-most population (pop. 7) in the ITS network (R11, Fig. 3A) is also congruent with an eastward migration from the western Pyrenees (Templeton, 1998). In agreement, this population showed a haplotype (H9) which was already found in the Central Pyrenees (pop. 6).

If we consider the distribution of the ancestral ribotype and haplotypes in the central area of the Iberian Peninsula, a peripheral colonisation trend may be inferred for different mountain ranges in Glaucoreseda species. Populations of $R$. complicata (pop. 3) and R. gredensis (pop. 5) located in the peripheral areas of the species range (Fig. 1B), are positioned as tip nodes in the plastid (H6) and ITS (R17) networks, respectively (Fig. 3), and their ribotypes/haplotypes are exclusive. This is consistent with recent colonisation events (Castelloe \& Templeton, 1994; Templeton, 1998). The western-most population of $R$. gredensis (pop. 5, Portugal) showed only one ribotype (R17), in contrast with populations in the core of the Central Range for which two to four ribotypes were found in clones and/or inferred by substraction (Fig. 1B; Table 1). Accordingly, a general trend of genetic diversity decreasing towards peripheral populations has been put forward in several studies (Durka, 1999; Lammi \& al., 1999). Therefore, in addition to the already proposed westward colonisation of the Pyrenees by R. glauca, an eastward colonisation of Sierra Nevada could be suggested for $R$. complicata, whereas a westward migration of $R$. gredensis in the Central Range may have occurred. This peripheral colonization pattern would be in agreement with Pleistocene vegetation history inferred from palaeoclimatic and palaeoecological data (Kaiser, 1969; Lang, 1994). Thus, montane areas in central-northern and eastern Iberian Peninsula were probably suitable for glacial survival of Glaucoreseda species, as they were covered by cold steppe/tundra vegetation, whereas peripheral parts were dominated by conifers and by deciduous forests near the coast (Costa-Tenorio \& al., 1990; Kropf \& al., 2006).

The evolutionary vicariance scenario proposed here is congruent with the previous cytogenetic hypothesis suggested by González Aguilera \& al. (1980), in which an ancestral diploid species could have undergone polyploidisation prior to fragmentation and subsequent speciation driven by Pleistocene climatic oscillations. Given that all Glaucoreseda species are tetraploids with the same chromosome number $(n=14 ; 2 n=28$; Fig. 1A), it appears more likely that the polyploidisation event took place prior to the range fragmentation and speciation. Although factors promoting polyploidisation are still a matter of discussion (Ramsey \& Schemske, 1998; Comai, 2005), it has frequently been associated with glaciations and colonisation of cold habitats in altitude and latitude (Stebbins, 1984; Parisod $\&$ Besnard, 2007). The derived chromosome basic number in Resedaceae $(x=7$; González Aguilera \& Fernández Peralta, 1984; Martín-Bravo \& al., 2007) and the chromosome number stability $(n=14 ; 2 n=28)$ also support the relatively recent origin of Glaucoreseda.

Dispersal across the Strait of Gibraltar. - While interglacial vicariance appears as the main process involved in the origin of Glaucoreseda species in the Iberian Peninsula, dispersal may have been involved in the origin of the Moroccan endemic $R$. battandieri. Our time estimates for the diversification of Glaucoreseda $(0.73 \pm 0.45 \mathrm{Ma}$, ITS; $0.60 \pm 0.48 \mathrm{Ma}$, cpDNA), and for the origin of $R$. battandieri $(0.29 \pm 0.40 \mathrm{Ma}$, ITS) are after the opening of the Strait of Gibraltar during the Pliocene (ca. 5.3 Ma; Krijgsman, 2002). In addition, R. battandieri sequences (R2-R5; H10) are positioned as tip nodes with respect to Iberian ancestral ribotype and haplotypes (R1, H1, H2; Fig. 3). We therefore postulate a dispersal from the Iberian Peninsula to Morocco to account for this monophyletic North African lineage. After the colonisation event, the Strait of Gibraltar probably acted as a barrier to gene flow, as described for other Ibero-North African plant lineages (reviewed in Rodríguez-Sánchez \& al., 2008). Despite the apparent lack of specific mechanisms for dispersal in Resedaceae, evidence of long-distance colonisation success in the family has also been reported for the Canarian endemic species of Reseda (MartínBravo \& al., 2007), as well as in Oligomeris, the sister-group of Glaucoreseda (Martín-Bravo \& al., 2009).

\section{CONCLUSIONS}

Range shifts induced by Quaternary climatic oscillations may have had an important effect in speciation of European mountain plant groups such as Reseda sect. Glancoreseda. Estimates of divergence times indicate a late Pleistocene diversification of Glaucoreseda. Hybridisation and incomplete lineage sorting may have been involved in the phylogenetic incongruence between nuclear and plastid phylogenies in Glaucoreseda. However, genealogical relationships of haplotypes 
suggest that incomplete lineage sorting of ancestral polymorphism due to recent divergence is probably the main cause. Vicariance appears to have been the main process involved in the speciation and present distribution of Glaucoreseda in the Iberian Peninsula, whereas long-distance dispersal could be related to the colonisation of North Africa by $R$. battandieri.

\section{- ACKNOWLEDGEMENTS}

We thank M. Míguez and F.J. Fernández for technical support; the curators of ARAN, M, MA, SALA and UPOS herbaria for the loan of specimens and granting permissions for DNA extractions; A. Fernández and M. Muñoz for essential help with the ITS cloning procedure; B. García and P. Jiménez-Mejías for providing plant material and help during collecting; and two anonymous reviewers for their critical comments on the manuscript. This work was supported by the Spanish Ministry of Science and Technology (CGL2005-06017-C02-02/BOS) and Andalusian Government (P06-RMM-4128).

\section{LITERATURE CITED}

Abdallah, M.S. \& de Wit, H.C.D. 1978. The Resedaceae: A taxonomical revision of the family (final instalment). Meded. Landbouwhoogeschool Wageningen 78: 1-416.

Al-Shehbaz, I.A., Beilstein, M.A. \& Kellogg, E.A. 2006. Systematics and phylogeny of the Brassicaceae (Cruciferae): An overview. Pl. Syst. Evol. 259: 89-120.

Albaladejo, R.G., Fuertes Aguilar, J., Aparicio, A. \& Nieto Feliner, G. 2005. Constrasting nuclear-plastidial phylogenetic patterns in the recently diverged Iberian Phlomis crinita and P. lychnitis lineages (Lamiaceae). Taxon 54: 987-998.

Alvarez, N., Thiel-Egenter, C., Tribsch, A., Holderegger, R., Manel, S., Schönswetter, P., Taberlet, P., Brodbeck, S., Gaudeul, M., Gielly, L., Küpfer, P., Mansion, G., Negrini, R., Paun, O., Pellecchia, M., Rioux, D., Schüpfer, F., Van Loo, M., Winkler, M., Gugerli, F. \& IntraBioDiv Consortium. 2009. History or ecology? Substrate type as a major driver of spatial genetic structure in Alpine plants. Ecol. Lett. 12: 632-640.

Caicedo, A.L. \& Schaal, B. 2004. Population structure and phylogeography of Solanum pimpinellifolium inferred from a nuclear gene. Molec. Ecol. 13: 1871-1882.

Castelloe, J. \& Templeton, A.R. 1994. Root probabilities for intraspecific gene trees under neutral coalescent theory. Molec. Phylog. Evol. 3: 102-113.

Clark, A.G. 1990. Inference of haplotypes from PCR-amplified samples of diploid populations. Molec. Biol. Evol. 7: 111-122.

Clement, M., Posada, D. \& Crandall K.A. 2000. TCS: A computer program to estimate gene genealogies. Molec. Ecol. 9: 1657-1659.

Comai, L. 2005. The advantages and disadvantages of being polyploid. Nature Rev. Genet. 6: 836-846.

Comes, H.P. \& Abbott, R.J. 2001. Molecular phylogeography, reticulation, and lineage sorting in Mediterranean Senecio sect. Senecio (Asteraceae). Evolution 55: 1943-1962.

Comes, H.P. \& Kadereit, J.W. 1998. The effect of Quaternary climatic changes on plant distribution and evolution. Trends Pl. Sci. 3: 432-438.

Comes H.P. \& Kadereit, J.W. 2003. Spatial and temporal patterns in the evolution of the flora of the European Alpine System. Taxon 52: $432-438$

Costa-Tenorio, M., García Antón, M., Morla, C. \& Sáinz Ollero, H. 1990. La evolución de los bosques en la península Ibérica: Una interpretación basada en datos paleobiogeográficos. Ecología 1: 315-358.

Dixon, C.J., Schönswetter, P. \& Schneeweiss, G.M. 2007. Traces of ancient range shifts in a mountain plant group (Androsace halleri complex, Primulaceae). Molec. Ecol. 16: 3890-3901.

Dubreuil, M., Riba, M. \& Mayol, M. 2008. Genetic structure and diversity in Ramonda myconi (Gesneriaceae): Effects of historical climate change on a preglacial relict species. Amer. J. Bot. 95: 577-857.

Durka, W. 1999. Genetic diversity in peripheral and subcentral populations of Corrigiola litoralis L. (Illecebraceae). Heredity 83: 476-484.

Escudero, M., Valcárcel, V., Vargas, P. \& Luceño, M. 2008. Evolution in Carex L. sect. Spirostachyae (Cyperaceae): A molecular and cytogenetic approach. Organisms Div. Evol. 7: 271-291.

Fuertes Aguilar, J. \& Nieto Feliner, G. 2003. Additive polymorphisms and reticulation in an ITS phylogeny of thrifts (Armeria, Plumbaginaceae). Molec. Phylog. Evol. 28: 430-447.

Gernandt, D.S., Liston, A. \& Piñero, D. 2001. Variation in the nrDNA ITS of Pinus subsection Cembroides: Implications for molecular systematic studies of Pine species complexes. Molec. Phylog. Evol. 21: 449-467.

Goloboff, P.A., Farris, S. \& Nixon, K. 2003. TNT: Tree analysis using new technology. Program and documentation avalaible at http:// www.zmuc.dk/public/phylogeny/tnt.

Gómez, A. \& Lunt, D.H. 2007. Refugia within refugia: Patterns of phylogeographic concordance in the Iberian Peninsula. Pp: 155-182 in: Weiss, S. \& Ferrand, N. (eds.), Phylogeography in southern European refugia: Evolutionary perspective on the origins and conservation of European biodiversity. Dordrecht, Amsterdam: Springer.

Gómez-Campo, C. \& Malato-Beliz, J. 1985. The Iberian Peninsula. Pp: 47-70 in: Gómez-Campo, C. (ed.), Plant conservation in the Mediterranean area. Dordrecht, Amsterdam: W. Junk.

González Aguilera, J.J. \& Fernández Peralta, A.M. 1984. Phylogenetic relationships in the family Resedaceae. Genetica 64: 185-197.

González Aguilera, J.J., Fernández Peralta, A.M. \& Sañudo, A. 1980. Estudios citogenéticos y evolutivos en especies españolas de la familia Resedaceae L. sección Glaucoreseda DC. Anales Inst. Bot. Cavanilles 36: 311-320.

Grimm, G.W. \& Denk, T. 2008. ITS evolution in Platanus (Platanaceae): Homoeologues, pseudogenes and ancient hybridization. Ann. Bot. 101: 403-419.

Hendry, A.P., Nosil, P. \& Rieseberg, L.H. 2007. The speed of ecological speciation. Functional Ecol. 21: 455-464.

Hewitt, G.M. 2000. The genetic legacy of the Quaternary ice ages. Nature 405: 907-913.

Hughes, P.D., Woodward, J.C. \& Gibbard, P.L. 2006. Quaternary glacial history of Mediterranean mountains. Progr. Phys. Geogr. 30: 334-364.

Iglesias, A., Little, S.A., Wilf, P. \& Gandolfo, M.A. 2008. An early Paleocene flower related to Resedaceae (Brassicales) bearing in situ pollen and cuticle from Patagonia, Argentina. P. 125 in: Schmidt-Sinns, J. (ed.), 8th International Organization of Palaeobotany Conference. August 30-September 5, Bonn, Germany. Berlin: GeoUnion Alfred-Wegener-Stiftung.

Jakob, S.S. \& Blattner, F.R. 2006. A chloroplast genealogy of Hordeum (Poaceae): Long-term persisting haplotypes, incomplete lineage sorting, regional extinction, and the consequences for phylogenetic inference. Molec. Biol. Evol. 23: 1602-1612.

Jobes, D.V. \& Thien, L.B. 1997. A conserved motif in the 5.8S ribosomal RNA (rRNA) gene is a useful diagnostic marker for plant Internal Transcribed Spacer (ITS) sequences. Pl. Molec. Biol. Reporter 15: 326-334.

Jones, T.A., Larson, S.R. \& Wilson, B.L. 2008. Genetic differentiation and admixture among Festuca idahoensis, F. roemeri and F. ovina detected in AFLP, ITS and chloroplast DNA. Botany 86: 422-434.

Kadereit, J.W. \& Comes, H.P. 2005. The temporal course of alpine 
plant diversification in the Quaternary. Pp. 117-130 in: Bakker, F.T., Chatrou, L.W., Gravendeel, B. \& Pelser, P. (eds.), Plant species systematics: New perspectives on pattern and process. Regnum Vegetabile 143. Königstein: Koeltz.

Kadereit, J.W., Griebeler, E.M. \& Comes, H.P. 2004. Quaternary diversification in European alpine plants: Patterns and process. Philos. Trans., Ser. B 359: 265-274.

Kaiser, K. 1969. The climate of Europe during the Quaternary ice age Pp. 10-37 in: Wright, H.E. (ed.), Quaternary geology and climate. Washington, D.C.: National Academy of Sciences.

Kelchner, S.A. 2000. The evolution of non-coding chloroplast DNA and its application in plant systematics. Ann. Missouri Bot. Gard. 87: 482-498.

Koch, M.A., Haubold, B. \& Mitchell-Olds, T. 2001. Molecular systematics of the Brassicaceae: Evidence from coding plastidic matK and nuclear CHS sequences. Amer. J. Bot. 88: 534-544.

Koch, M.A. \& Matschinger, M. 2007 . Evolution and genetic differentiation among relatives of Arabidopsis thaliana. Proc. Natl. Acad. Sci. U.S.A 104: 6272-6277.

Krijgsman, W. 2002. The Mediterranean: Mare Nostrum of Earth Sciences. Earth Planet. Sci. Lett. 205: 1-12.

Kropf, M., Comes, H.P. \& Kadereit, J.W. 2006. Long-distance dispersal $v s$ vicariance: The origin and genetic diversity of alpine plants in the Spanish Sierra Nevada. New Phytol. 172: 169-184.

Kropf, M., Comes, H.P. \& Kadereit, J.W. 2008. Causes of the genetic architecture of southwest European high -mountain disjuncts. $P l$. Ecol. Div. 1: 217-228.

Kropf, M., Kadereit, J.W. \& Comes, H.P. 2003. Differential cycles of range contraction and expansion in European high mountain plants during the Late Quaternary: Insights from Pritzelago alpina (L.) O. Kuntze (Brassicaceae). Molec. Ecol. 12: 931-949.

Lammi, A., Siikamaki, P. \& Mustajarvi, K. 1999. Genetic diversity, population size, and fitness in central and peripheral populations of a rare plant Lychnis viscaria. Cons. Biol. 13: 1069-1078.

Lang, G. 1994. Quartäre Vegetationsgeschichte Europas. Stuttgart: Fischer.

Liu, J.S. \& Schardl, C.L. 1994. A conserved sequence in internal transcribed spacer 1 of plant nuclear rRNA genes. Pl. Molec. Biol. 26: 775-778

Martín-Bravo, S., Meimberg, H., Luceño, M., Märkl, W., Valcárcel, V., Bräuchler, C., Vargas, P. \& Heubl, G. 2007. Molecular systematics and biogeography of Resedaceae based on ITS and trnL-F sequences. Molec. Phylog. Evol. 44: 1105-1120.

Martín-Bravo, S., Vargas, P. \& Luceño, M. 2009. Is Oligomeris (Resedaceae) indigenous to North America? Molecular evidence for a natural colonization from the Old World. Amer. J. Bot. 96: 507-518.

Médail, F. \& Quézel, P. 1997. Hot-spots analysis for a conservation of plant biodiversity in the Mediterranean basin. Ann. Missouri Bot. Gard. 84: 112-128.

Nieto Feliner, G., Gutiérrez Larena, B. \& Fuertes Aguilar, J. 2004. Fine-scale geographical structure, intra-individual polymorphism and recombination in nuclear ribosomal Internal Transcribed Spacers in Armeria (Plumbaginaceae). Ann. Bot. 93: 189-200.

Noyes, R.D. 2006. Intraspecific nuclear ribosomal DNA divergence and reticulation in sexual diploid Erigeron strigosus (Asteraceae). Amer. J. Bot. 93: 470-479.

Olsen, K.M. \& Schaal, B.A. 1999. Evidence on the origin of cassava: Phylogeography of Manihot esculenta. Proc. Natl. Acad. Sci. U.S.A 96: 5586-5591.

Parisod, C. \& Besnard, G. 2007. Glacial in situ survival in the Western Alps and polytopic autopolyploidy in Biscutella laevigata L. (Brassicaceae). Molec. Ecol. 16: 2755-2767.

Pleines, T., Jakob, S.S. \& Blattner, F.R. 2009. Application of noncoding DNA regions in intraspecific analyses. Pl. Syst. Evol. 282: 281-294.

Posada, D. \& Buckley, T.R. 2004. Model selection and model averaging in phylogenetics: Advantages of Akaike information criterion and Bayesian approaches over likelihood ratio tests. Syst. Biol. 53: 793-808.

Puscas, M., Choler, P., Tribsch, A., Gielly, L., Rioux, D., Gaudeul, M. \& Taberlet, P. 2008. Post-glacial history of the dominant alpine sedge Carex curvula in the European Alpine System inferred from nuclear and chloroplast markers. Molec. Ecol. 17: 2417-2429.

Ramsey, J. \& Schemske, D.W. 1998. Pathways, mechanisms, and rates of polyploidy formation in flowering plants. Annual Rev. Ecol. Syst. 29: 467-501.

Ray, N. \& Adams, J.M. 2001. A GIS-based vegetation map of the world at the Last Glacial Maximum (25,000-15,000 BP). Internet Archaeol. 11. Available at http://intarch.ac.uk/journal/issue11/ rayadams index.html.

Rodríguez-Sánchez, F., Pérez-Barrales, R., Ojeda, F., Vargas, P. \& Arroyo, J. 2008. The Strait of Gibraltar as a melting pot for plant biodiversity. Quatern. Sci. Rev. 27: 2100-2117.

Ronquist, F. \& Huelsenbeck, J.P. 2003. MrBayes 3: Bayesian phylogenetic inference under mixed models. Bioinformatics 19: 1572-1574.

Rosselló, J.A., Lázaro, A., Cosín, R. \& Molins, A. 2007. A phylogeographic split in Buxus balearica (Buxaceae) as evidenced by nuclear ribosomal markers: When ITS paralogues are welcome. J. Molec. Evol. 64: 143-157.

Sanderson, M.J. 2004. r8s, version 1.70. User's manual. Available from http://loco.biosci.arizona.edu/r8s/.

Sang, T., Crawford, D. \& Stuessy, T.F. 1995. Documentation of reticulate evolution in peonies (Paeonia) using internal transcribed spacer sequences of nuclear ribosomal DNA: Implications for biogeography and concerted evolution. Proc. Natl. Acad. Sci. U.S.A 92: 6813-6817.

Schaal, B.A., Hayworth, D.A., Olsen, K.M., Rauscher, J.T. \& Smith, W.A. 1998. Phylogeographic studies in plants: Problems and prospects. Molec. Ecol. 7: 465-474.

Schluter, D. 1996. Ecological causes of adaptive radiation. Amer. Naturalist 148 (Suppl.): S40-S64.

Schönswetter, P., Stehlik, I., Holderegger, R. \& Tribsch, A. 2005. Molecular evidence for glacial refugia of mountain plant in the European Alps. Molec. Ecol. 14: 3547-3555.

Segarra-Moragues, J.G., Palop-Esteban, M., González-Candelas, F. \& Catalán, P. 2007a. Nunatak survival vs. tabula rasa in the Central Pyrenees: a study on the endemic plant species Borderea pyrenaica (Dioscoreaceae). J. Biogeogr. 34: 1893-1906.

Segarra-Moragues, J.G., Villar, L., López, J., Pérez-Collazos, E. \& Catalán, P. 2007b. A new Pyrenean hybrid Cirsium (Asteraceae) as revealed by morphological and molecular analyses. Bot. J. Linn. Soc. 154: 421-434.

Silvertown, J. \& Charlesworth, D. 2001. Introduction to plant population biology. Oxford: Blackwell.

Stebbins, G.L. 1984. Polyploidy and the distribution of the arctic-alpine flora: New evidence and a new approach. Bot. Helvet. 94: 1-13.

Suárez-Santiago, V.N., Salinas, M.J., García-Jacas, N., Soltis, P.S., Soltis, D.E. \& Blanca, G. 2007. Reticulate evolution in the Acrolophus subgroup (Centaurea L., Compositae) from the Western Mediterranean: Origin and diversification of section Willkommia Blanca. Molec. Phylog. Evol. 43: 156-172.

Suc, J.P. 1984. Origin and evolution of the Mediterranean vegetation and climate in Europe. Nature 307: 429-432.

Swofford, D.L. 2002. PAUP*: Phylogenetic analysis using parsimony (*and other methods), version 4.0b10. Sunderland, Massachusetts: Sinauer.

Templeton, A.R. 1998. Nested clade analyses of phylogeographic data: Testing hypotheses about gene flow and population history. Molec. Ecol. 7: 381-397.

Valdés, B. 1991. Andalucía and the Rif: Floristic links and common flora. Bot. Chron. (Patras) 10: 117-124

Valdés Bermejo, E. 1993. Reseda L. Pp. 440-475 in: Castroviejo, S., Aedo, C., Gómez Campo C., Laínz, M., Montserrat, P., Morales, 
R., Muñoz Garmendia, F., Nieto Feliner, G., Rico, E., Talavera, S. \& Villar, L., (eds.), Flora Iberica, vol. 4. Madrid: Consejo Superior de Investigaciones Científicas.

Vargas, P. 2003. Molecular evidence for multiple diversification patterns of alpine plants in Mediterranean Europe. Taxon 52: 463-476.

Vargas, P., Carrió, E., Guzmán, B., Amat, E. \& Güemes, J. 2009. A geographical pattern of Antirrhinum (Scrophulariaceae) speciation since the Pliocene based on plastid and nuclear DNA polymorphisms. J. Biogeogr. 36: 1297-1312.

Verboom, G.A., Linder, H.P. \& Stock, W.D. 2004. Testing the adaptive nature of radiation: Growth form and life history divergence in the African grass genus Ehrharta (Poaceae: Ehrhartoideae). Amer. J. Bot. 91: 1364-1370.

Villar, L. \& Laínz, M. 1990. Plantes endémiques des Pyrénees Occidentales et des Monts Cantabres: Essai chorologique. Pp. 209-234 in: Villar, L. (ed.), Botánica Pirenaico-Cantábrica. Monografias del Instituto Pirenaico de Ecología 5. Huesca: Instituto de Estudios Altoaragoneses and Instituto Pirenaico de Ecología.

Wendel, J.F. \& Doyle, J.J. 1998. Phylogenetic incongruence: Window into genome history and molecular evolution. Pp. 265-296 in: Soltis, D.E., Soltis, P.S. \& Doyle, J.J. (eds.), Molecular systematics of plants II. DNA sequencing. Boston: Kluwer Academic Publishers.

Wichman, S.R., Wright, S.D., Cameron, E.K., Keeling, D.J. \& Gardner, R.C. 2002. Elevated genetic heterogeneity and Pleistocene climatic instability: Inferences from nrDNA in New Zealand Coprosma (Rubiaceae). J. Biogeogr. 29: 943-954.

Wikström, N., Savolainen, V. \& Chase, M.W. 2001. Evolution of the angiosperms: Calibrating the family tree. Proc. Roy. Soc. London, Ser. B, Biol. Sci. 268: 1-10.

Zhang, D.X. \& Hewitt, G.M. 2003. Nuclear DNA analyses in genetic studies of populations: Practice, problems and prospects. Molec. Ecol. 12: 563-584. Zhang, L.B., Comes, H.P. \& Kadereit, J.W. 2001. Phylogeny and Quaternary history of the European montane/ alpine endemic Soldanella (Primulaceae) based on ITS and AFLP variation. Amer. J. Bot. 88: 2231-2345.

Zhang, L.B., Comes, H.P. \& Kadereit, J.W. 2004. The temporal course of Quaternary diversification in the European high mountain endemic Primula sect. Auricula (Primulaceae). Int. J. Pl. Sci. 165: 191-207. 